\title{
Report on the International AFIR Colloquium 2003, Maastricht, The Netherlands
}

From 17 to 19 September, 2003, Maastricht was the venue for the annual AFIR Colloquium. In this report you will find impressions of both the content and the surrounding social activities.

\section{PARTICIPATION}

The number of participants was 154 with 23 accompanying persons. There was a good spread over 22 countries. Apart from The Netherlands, which as a host country not surpisingly had the highest number (52), the Nordic countries stood out with 43 participants. Worthwhile mentioning also is Slovenia with 14 participants and the fact that seven countries were each represented by 1 participant.

\section{INVITED LECTURERS}

Two invited lecturers had been invited. Firstly, Mr Luc Henrard, Chief Risk Officer of FORTIS, Belgium, gave a lecture under the title "The management of a financial conglomerate: a challenge for the actuaries?". He made an almost passionate plea for actuaries to broaden their horizon to include more expertise outside their traditional role. Secondly, Mr Roderick Munsters, Chief Investment Officer of PGGM, The Netherlands, made a presentation on "The actuary and the investor on a rollercoaster ride" in which he, referring to PGGM's investment policies, equally challenged the actuaries to intensify their cooperation with the "asset specialists". Both presentations tied in very well with the subjects of of the regular papers and the special paper, mentioned below.

\section{PAPERS}

The number of accepted papers was 35 . Most of them were presented by the author (or one of the authors) during 30-minute sessions. The variety of subjects was quite interesting and all papers were classified in one of the three predefined categories, i.e. "Asset Classification", "Market valuation of Liabilities" and "Risk Measurement and Management". They are all accessible and downloadable through the website www.afir2003.nl, which will remain open for some time. We hope that a number of them will be published in the ASTIN Bulletin.

\section{SPECIAL PAPER}

One non-scientific paper was presented about "the future of AFIR" and the dual role of dealing with both traditional and new areas. The authors made a plea for a reorientation of AFIR's "mission". In their view, AFIR should become more active in stimulating actuaries to become "risk officers" in a far more general sense. Of course this would include adjustments to the educational 
syllabuses. The paper also described - on the basis of a survey in 10 countries - the extremely diverse way in which presently AFIR activities are organised around the world.

\section{General meeting and Bob Alting von Geusau Memorial Prize}

On Friday afternoon the General Meeting for AFIR members was held to discuss accounts, Committee membership nominations and some other topics of a more formal nature. The Chairman also announced that the discussion on the future of AFIR would have a follow-up during the next Colloquium and that several sub-committees had been appointed to prepare for this. Following the General Meeting, a ceremony took place to present a Prize for the best article, published in the ASTIN Bulletin during the years 2001 and 2002. It was the first time this new annual Prize, named after one of the "founding fathers" of AFIR in the seventies, was awarded. The winner was Shaun Wang for his paper "A framework for pricing financial and insurance risks" in the ASTIN Bulletin 32.2 of November 2002.

\section{SOCIAL PROGRAM}

A number of social activities had been arranged for participants and companions to liaise with others "outside the world of formulae". On the opening day (Wednesday) a tour of the surrounding area of Maastricht was made, ending with a reception at Maastricht's Town Hall. There was a companion's program on Thursday and in the evening all guests were invited to an informal dinner in the city. Finally, there was a formal farewell dinner on Friday night in one of the castles in Maastricht's province of Limburg.

\section{NeXt Colloquium}

During the General Meeting the venue for the next Colloquium was disclosed: USA, (probably New York) in November 2004. On behalf of the Organising and Scientific Committees I take pleasure in wishing our successors the very best in preparing for that event! 